\title{
The Elution Behaviour of Scrapie Brain Tissue Through Calcium Phosphate Columns
}

\author{
By D. L. MOULD, W. SMITH and A. McL. DAWSON \\ Animal Diseases Research Association, Moredun Institute, Edinburgh, 9
}

(Received 4 February 1964)

\begin{abstract}
SUMMARY
During the investigation of procedures for the isolation and characterization of the agent causing scrapie disease in sheep a study of the elution behaviour of scrapie brain preparations from sheep, goats and mice on calcium phosphate columns was made. Eluates of increasing phosphate concentration were tested for biological activity in the sheep and mouse. Adsorption on calcium phosphate columns did not provide a satisfactory method for concentration of the biologically active scrapie agent from untreated homogenates; only a 10-fold purification of the agent was achieved. The activity always appeared in the pelleted sediment after high-speed centrifugation of the eluates. Ether treatment of the tissue can alter the elution behaviour. The elution data have been interpreted as indicating species variation in the binding of the agent to brain tissue.
\end{abstract}

\section{INTRODUCTION}

Experimental investigation of scrapie, a degenerative disease of sheep, has recently increased since a form of the disease has been produced in mice following inoculation with brain material from scrapie-affected goats (Chandler, 1961, 1963) and scrapie-affected sheep (Zlotnik \& Rennie, 1963). Quantitative studies on the nature of the disease involving titrations in large numbers of animals previously impracticable have already been reported (Hunter, Millson \& Chandler, 1963; Hunter, Millson \& Meek, 1964).

Earlier experimental procedures directed towards the isolation and characterization of the scrapie agent indicated that the active agent was associated with a particulate entity either existing independently or in close combination with undefined tissue fragments (Mould \& Smith, 1962 $a, b$ ). These findings were confirmed and extended by the recent results of Hunter, Millson \& Meek (1964) that mouse scrapie infectivity was found to reside in the mitochondrion-sized fraction from scrapie mouse brain homogenates. We reached similar conclusions (Mould, Dawson \& Smith, 1964) from studies with a different strain of mouse scrapie (ME 7) derived from a naturally occurring case of scrapie in a Suffolk sheep (Zlotnik \& Rennie, 1963). This differs from the strain used by Hunter et al. in that the histopathology of the disease in mice is indistinguishable from that in the original sheep host.

In the sheep and goat investigations (Mould \& Smith, 1962 $a, b$ ) the scrapie activity held in the tissue sediments could be partially recovered by extraction with buffered saline. This led to the possibility of adsorption of the tissue suspensions on 
calcium phosphate columns and elution with progressively increasing phosphate concentration, according to the technique already successfully used as a method of virus purification (Taverne, Marshall \& Fulton, 1958; Taverne \& Wildy, 1959; Wildy, Stoker, Macpherson \& Horne, 1960; Faulkner et al. 1961). A convenient medium was thereby provided for studying the effect of elution with increasing salt concentration at controlled $\mathrm{pH}$ and also for characterizing any virus-like nature of the scrapie agent by the chromatographic adsorption behaviour that it might exhibit on the column. The elution of sheep scrapie material through such a packed column followed by testing in sheep provided stimulating results but the limited data do not permit unequivocal interpretation. The adsorption behaviour of scrapie activity in sheep, goat and mouse brain tissue preparations was investigated further by biological testing of the eluates in the mouse. Some results have been reported in brief communications (Mould, Smith \& Dawson, 1963, 1964).

\section{METHODS}

Calcium phosphate. The adsorbent was prepared according to the method of Taverne et al. (1958). Two standard columns of $15 \mathrm{~mm}$. and $8 \mathrm{~mm}$. internal diam. were used with a packed volume of 15 and $3 \mathrm{ml}$. respectively. Dilute phosphate buffers for column elution at a constant $\mathrm{pH}(7 \cdot 0)$ were prepared from stock $1 \cdot 0 \mathrm{M}$ phosphate buffer consisting of $0 \cdot 66 \mathrm{M}-\mathrm{Na}_{2} \mathrm{HPO}_{4}$ and $0 \cdot 33 \mathrm{M}-\mathrm{KH}_{2} \mathrm{PO}_{4}$ at $\mathrm{pH} 6 \cdot 8$.

Fractionation of scrapie sheep brain (Cheviot) and inoculation in sheep. The source of scrapie material was a frozen scrapie-infected Cheviot sheep brain obtained as a further passage SSBP/Strain 1/Pass. 22 of the Cheviot strain at the Moredun Institute (Stamp et al. 1959).

All extraction procedures were done at $4^{\circ}$. The infected brain $(80 \mathrm{~g}$.$) was homo-$ genized and ether $(800 \mathrm{ml}$.) slowly added during homogenization. After separation of the ether layer by centrifugation extraction was repeated with fresh ether. The extracted residue was suspended in $0.05 \mathrm{M}$-phosphate buffer, centrifuged at $500 \mathrm{~g}$ and residual ether evaporated from the aqueous layer under reduced pressure. The suspension was centrifuged for $30 \mathrm{~min}$. at $1740 \mathrm{~g}$, the supernatant removed and centrifuged for $2 \mathrm{hr}$ at $150,000 \mathrm{~g}$ (Spinco Model L, No. 40 rotor at $40,000 \mathrm{rev} . / \mathrm{min}$ ). The pelleted deposits were resuspended in $0.05 \mathrm{M}$-phosphate buffer $(36 \mathrm{ml}$.) and clarified by light centrifugation. A portion $\left(16 \mathrm{ml}\right.$.) of the supernatant $\left(\mathrm{S}_{1}\right)$ was taken for inoculation and the remainder for elution through a calcium phosphate column (elution volume, $15 \mathrm{ml}$.)

The supernatant fluid $\left(\mathrm{S}_{1}\right)$ was allowed to run into the packed column under atmospheric pressure and washed in with $0.05 \mathrm{M}$-phosphate buffer $(5 \mathrm{ml}$.) followed by equal volumes (15 ml.) of $0 \cdot 1,0 \cdot 2,0 \cdot 3,0 \cdot 4$ and $0.5 \mathrm{M}$-phosphate buffer. Corresponding successive volumes of eluate were collected and dialysed against distilled water and each fraction centrifuged for $2 \mathrm{hr}$ at $150,000 \mathrm{~g}$. The pelleted deposits from the $0.05 \mathrm{M}$ eluate, pooled $0 \cdot 1,0.2,0.3 \mathrm{M}$ eluates, and pooled $0.4,0.5 \mathrm{M}$ eluates were resuspended in sterile saline ( $16 \mathrm{ml}$.) for inoculation.

Cheviot wether hoggs, aged about 6 months at the time of inoculation and used before the time that natural scrapie would be expected to develop, were housed and fed as described by Stamp et al. (1959). Separate groups of fifteen sheep were inoculated $\left(1 \mathrm{ml}\right.$.) by the intracerebral route with the supernatant $\left(\mathrm{S}_{1}\right)$ applied to the 
column and the three eluate fractions. The experimental sheep were discarded 10 months after inoculation. The appearance of clinical symptoms of incoordination and rubbing followed by the continuous decline of the animal were taken as criteria for the diagnosis of scrapie.

Fractionation of scrapie sheep brain (Suffolk) and inoculation into mice. The source of scrapie material for final inoculation in mice was a frozen homogenized pool (SS/3/Source) of four brains collected from Suffolk sheep affected with natural scrapie and tested by passage in sheep. A portion (65 g.) of the brain pool was homogenized in $0.85 \%$ saline to give a final $20 \%(\mathrm{w} / \mathrm{v})$ homogenate and centrifuged for $30 \mathrm{~min}$. at $1740 \mathrm{~g}$. The supernatant (S) was decanted and a sample (10 $\mathrm{ml}$.) taken for inoculation. Extraction of the sediment was repeated with saline (100 $\mathrm{ml}$.) followed again by low-speed centrifugation. The two supernatants were pooled and centrifuged for $2 \mathrm{hr}$ at $150,000 \mathrm{~g}$ to give complete sedimentation. The pelleted deposits were homogenized in $0.05 \mathrm{M}$-phosphate buffer and the suspension clarified by centrifugation for $1 \mathrm{~min}$. at $9000 \mathrm{~g}$.

A portion (4 ml.) of the supernatant fluid $\left(S_{1}\right)$ was retained for inoculation. The remainder (18.5 ml.) was run into a calcium phosphate column (elution volume $15 \mathrm{ml}$.) under atmospheric pressure at room temperature and washed through with $0.05 \mathrm{M}$-phosphate buffer $(30 \mathrm{ml}$.) followed by equal volumes $(15 \mathrm{ml}$.) of increasing concentration. Corresponding successive volumes of eluate were collected. The large volume $(50 \mathrm{ml}$.) of $0.05 \mathrm{M}$ eluate was centrifuged for $2 \mathrm{hr}$ at $145,000 \mathrm{~g}$ and the pellets (5) stored at $-20^{\circ}$. The other eluates $(15 \mathrm{ml}$.) were dialysed against $0.05 \mathrm{M}$ phosphate buffer and each eluted again through freshly packed calcium phosphate columns. During the repeat procedure with each fraction the suspension was washed in with $0.05 \mathrm{M}$-phosphate buffer $(30 \mathrm{ml}$.) followed by its previous appropriate phosphate eluting concentration $(15 \mathrm{ml}$.) Only the second eluate $(15 \mathrm{ml}$.) was collected. The separate eluates were dialysed against $0.05 \mathrm{M}$-phosphate buffer and then centrifuged for $2 \mathrm{hr}$ at $145,000 \mathrm{~g}$. The two pelleted deposits from each eluate were stored at $-20^{\circ}$.

Swiss white mice of the Moredun Institute stock were used and inoculated when 4-6 weeks old. Five groups of thirty mice were inoculated $(0 \cdot 03 \mathrm{ml}$.) by the intracerebral route with the following scrapie preparations. (1) The supernatant fluid (S) from the $20 \%$ homogenate was diluted with an equal volume of sterile saline. (2) The supernatant $\left(\mathrm{S}_{1}\right)$ applied to the column was also diluted in the same proportion. (3) One pellet from the $0.05 \mathrm{~m}$ eluate was taken up in sterile saline ( $2 \mathrm{ml}$.). (4) One pellet from each of the $0 \cdot 1,0 \cdot 2$ and $0 \cdot 3 \mathrm{M}$ repeat eluates was taken up and all were pooled in saline $(2 \mathrm{ml}$.). (5) One pellet each from the 0.4 and $0.5 \mathrm{~m}$ repeat eluates was taken up and each was pooled in sterile saline $(2 \mathrm{ml}$.).

The mice were kept until definite clinical symptoms of scrapie in mice as described by Zlotnik \& Rennie (1963) were apparent throughout the first group, when all mice were killed by decapitation. The brains of mice were removed immediately, fixed in $10 \%$ formol saline and prepared for histological examination (Zlotnik \& Rennie, 1962).

Fractionation of scrapie goat brain ('scratching' type). An identical procedure was carried out concurrently using as a source of scrapie material a frozen brain collected from a goat clinically affected by the disease in the course of passage transmission of scrapie in the goat, SGB/Pass 6 (Mould \& Smith, 1962b). A comparable 
amount of brain tissue was used and similar numbers and groups of mice were inoculated.

Fractionation of scrapie mouse brain (Chandler strain). An extraction procedure was applied to mouse brain tissue similar to that described by Mould \& Smith (1962 a) for the extraction of sheep brain tissue and possible concentration of the scrapie agent. The source of mouse scrapie material was a pool of eighteen mouse brains collected from clinical cases after the passage of Chandler strain mouse scrapie (Chandler, 1961, 1963), originating from a goat, in Moredun Institute stock Swiss white mice. The pooled brains (6 g.) were made up to a $10 \%(\mathrm{w} / \mathrm{v})$ homogenate with $0.85 \%$ saline. The saline extract was adjusted to $\mathrm{pH} 4$ and precipitated with $15 \%(\mathrm{w} / \mathrm{v})$ methanol. The sediment was then extracted with $\mathrm{pH} 9 \cdot 0$ saline $\left(0 \cdot 88 \mathrm{M}-\mathrm{NaCl}, 0.04 \mathrm{M}-\mathrm{Na}_{2} \mathrm{HPO}_{4}\right.$ adjusted to $\mathrm{pH} 9 \cdot 0$ with $\left.0.1 \mathrm{M}-\mathrm{NaOH}\right)$ and reprecipitated after dilution at $\mathrm{pH} 4 \cdot 5$, with final suspension again in $\mathrm{pH} 9 \cdot 0$ saline $(2.5 \mathrm{ml}$.). A sample $(0.2 \mathrm{ml}$.) was removed and dialysed against $0.85 \%$ saline for inoculation. The remainder $(2 \mathrm{ml}$.) was dialysed against $0.05 \mathrm{M}$-phosphate buffer and allowed to run into a calcium phosphate column (elution volume $3 \mathrm{ml}$.) After washing with $0.05 \mathrm{M}$-phosphate $(1 \mathrm{ml}$.) the column was eluted stepwise with the usual series of phosphate concentrations $(3 \mathrm{ml}$.) and the various eluates collected (3 ml.). All eluates were dialysed against saline and kept frozen $\left(-20^{\circ}\right)$ before inoculation in mice.

Swiss white mice were inoculated intraperitoneally $(0.5 \mathrm{ml}$.) when aged 8-12 weeks. Eight groups of fifteen mice were inoculated with the original $10 \%$ brain homogenate, the extract applied to the column and each individual phosphate concentration eluate after dilution to $10 \mathrm{ml}$. of inoculum. The mice were all destroyed 10 months after inoculation and the brains examined histologically.

Fractionation of scrapie mouse brain (Suffolk strain) and inoculation into mice. An ether extraction procedure similar to that applied to scrapie Cheviot sheep brain was repeated with a pool of scrapie mouse brain and a quantitative estimate of the spread of activity in the final fractions obtained by titration in mice. The source of scrapie material was a pool of eighteen brains harvested from clinically affected mice, being the second intracerebral passage in mice of mouse scrapie brain originating from scrapie Suffolk spleen administered by the intragastric route (Zlotnik \& Rennie, 1962, 1963). This strain has a well-established histological and clinical pattern and is being used extensively for mouse scrapie investigation at the Moredun Institute.

The brains were ground to a coarse powder in the frozen state and a portion ( $4 \cdot 9 \mathrm{~g}$.) homogenized in ether $(50 \mathrm{ml}$.). The procedure already described was followed and the final centrifuged pellets resuspended in $0.05 \mathrm{M}$-phosphate buffer $(5 \mathrm{ml}$.) and clarified by centrifugation for $1 \mathrm{~min}$. at $25,000 \mathrm{rev} . / \mathrm{min}$. (Spinco SW 39 rotor). A portion (1 ml.) was taken for inoculation and the remainder $(3 \cdot 3 \mathrm{ml}$.) applied to a freshly prepared calcium phosphate column (elution volume, $3 \mathrm{ml}$.). The column was eluted with $0.05 \mathrm{M}$-phosphate $(2 \mathrm{ml}$.) followed by equal volumes $(3 \mathrm{ml}$.) of the 0.1 to $0.5 \mathrm{M}$-phosphate concentrations, corresponding volumes of eluates being collected. All the eluates and the sample $(1 \mathrm{ml}$.) taken from the final supernatant were pelleted by centrifugation for $60 \mathrm{~min}$. at $35,000 \mathrm{rev} . / \mathrm{min}$. (Spinco SW 39 rotor) and the pellets frozen $\left(-20^{\circ}\right)$. The seven frozen pellets were resuspended in sterile saline ( $2 \mathrm{ml}$.). , A small portion ( $0.5 \mathrm{~g}$.) of the original ground mouse brain pool 
was homogenized in $0.85 \% \mathrm{NaCl}$ and made up to $10 \%(\mathrm{w} / \mathrm{v}, 5 \mathrm{ml}$.). All the suspensions were centrifuged for $1 \mathrm{~min}$. at 25,000 rev./min. (Spinco 40 rotor) for clarification.

A total of 392 Swiss white mice of the Moredun Institute stock were used and were 3-6 weeks old when inoculated. Serial 10-fold dilutions of the homogenate and each of the fractions were prepared in sterile saline and seven mice inoculated intracerebrally $\left(0.03 \mathrm{ml}\right.$.) at $10^{-1}$ to $10^{-7}$ dilution of each preparation. All the mice were killed by decapitation exactly 6 months after inoculation and the brains examined histopathologically for the unequivocal appearance of lesions indicative of scrapie.

\section{RESULTS}

\section{Properties of calcium phosphate columns}

The preparation of calcium phosphate needs care or otherwise the adsorbent properties for large molecules can be variable (Tiselius, Hjerten \& Levin, 1956). In general, the characteristic behaviour of the experimental material on the column

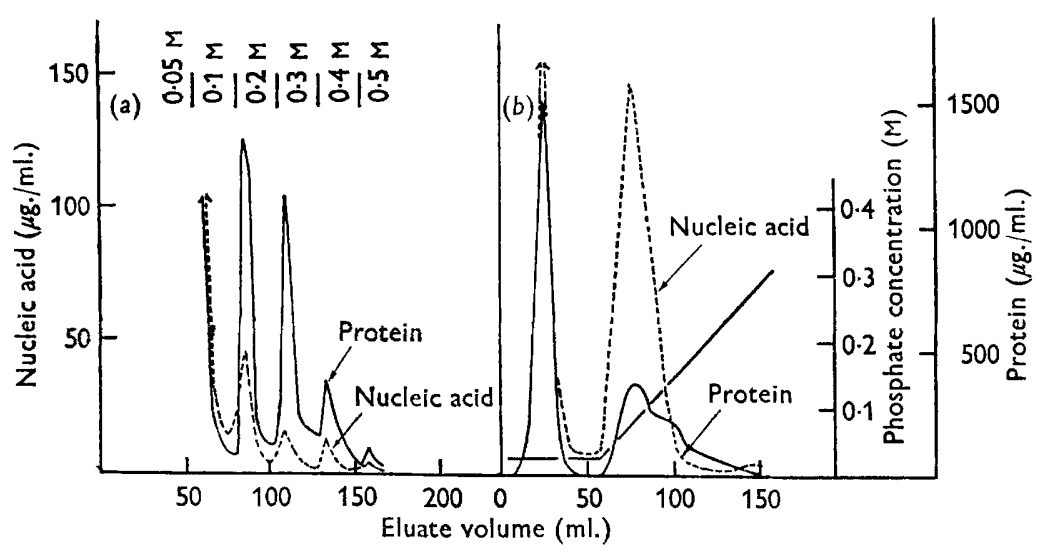

Fig. 1. Elution of ether-extracted brain tissue preparations through calcium phosphate columns. (a) Stepwise elution with increasing phosphate concentration. (b) Gradient elution with linearly increasing phosphate concentration.

serves as its own standard for reproducibility, but, in the present case where differing extraction procedures of the applied suspension could very well lead to an unknown variation in behaviour, this form of control is no longer practicable. All the various batches of calcium phosphate were freshly prepared and used within a week. During the course of this work similar calcium phosphate preparations were used for purification studies on contagious pustular dermatitis virus (orf) and cattle wart disease virus with satisfactory elution of the large orf virus with $0.5 \mathrm{M}$-phosphate and the smaller wart virus with $0 \cdot 3 \mathrm{M}$-phosphate (W. Smith, unpublished).

To ascertain the performance of the columns, preparations of ether-extracted brain tissue similar to those used for the biological experiments were eluted under increasing phosphate concentrations. The eluate fractions $(4 \mathrm{ml}$.) were assayed for total protein (Lowry, Rosebrough, Farr \& Randall, 1951) and total nucleic acid 
(Logan, Manwell \& Rossiter, 1952). During the stepwise elution of the column (Fig. 1 1 ) the bulk of the applied suspension passed through the column at the 0.05 and $0.1 \mathrm{~m}$ level followed by a series of decreasing peaks at the front of each concentration increment. The $0.05 \mathrm{M}$ eluate always contained particulate matter and the $0.2 \mathrm{~m}$ front also was usually cloudy in appearance. The composition of the eluate under gradient elution with linearly increasing phosphate concentration is shown in Fig. $1 b$. The extract was run into the column in $0.02 \mathrm{M}$-phosphate, washed in with the same buffer $(20 \mathrm{ml}$.) and eluted in a gradient increasing from 0.02 to $0 \cdot 4 \mathrm{M}$-phosphate. This illustrated more clearly the elution of unadsorbed material followed by a peak of nucleic acid and protein within the $0 \cdot 05-0.1 \mathrm{M}$ range of concentration gradually reducing as the effective phosphate concentration increased. These observations are in agreement with the general properties of calcium phosphate columns (Faulkner et al. 1961) and it has, therefore, been assumed that the adsorbent was both satisfactory and reproducible.

\section{Inoculation of sheep fraction (Cheviot) into sheep}

It has been shown that the scrapie activities of the tissue residue after extraction with solvents such as ether, butanol or chloroform-methanol have not been drastically reduced (Mould \& Smith, 1962 $a, b$; Butler \& Smith, 1960). The removal of lipid constituents from brain tissue homogenates simplified experimental difficulties both in centrifugation procedures and adsorption chromatography on columns.

Table 1. Incidence of scrapie in sheep inoculated with calcium phosphate column eluates of ether-extracted scrapie sheep (Cheviot) brain

\begin{tabular}{|c|c|c|c|}
\hline \multicolumn{4}{|c|}{ (For experimental details see text.) } \\
\hline Expt. no. & Inoculum & $\begin{array}{l}\text { No. of sheep } \\
\text { inoculated }\end{array}$ & $\begin{array}{l}\text { No. of } \\
\text { cases }\end{array}$ \\
\hline $60 / 10 / 1$ & $\mathbf{S}_{1}$ & 15 & 3 \\
\hline $60 / 10 / 2$ & $0.05 \mathrm{M}$ & 15 & 2 \\
\hline $60 / 10 / 3$ & $\left.\begin{array}{l}0 \cdot 1 \mathrm{M} \\
0 \cdot 2 \mathrm{M} \\
0 \cdot 3 \mathrm{M}\end{array}\right\}$ & 15 & 4 \\
\hline $60 / 10 / 4$ & $\left.\begin{array}{l}0 \cdot 4 M \\
0.5 M\end{array}\right\}$ & 15 & 5 \\
\hline
\end{tabular}

For reasons of economy in experimental animals the eluates were combined together into two inoculum pools. The number of sheep developing clinical scrapie after 10 months are given in Table 1 . From accumulated evidence over 400 Cheviot sheep exposed to a standard scrapie inoculum it has been established that about one-third are susceptible to experimental scrapie. The number of cases arising in the various groups are, therefore, well within this range, and it is impossible to assess the relative infectivity except to estimate that the fractions probably do not vary more than 100-fold in activity. The appearance of appreciable activity in the pooled column eluates and particularly in the later stages was, however, of interest. 


\section{Inoculation of sheep fractions (Suffolk) and goat fractions into mice}

The minimum amount of treatment was given to the homogenized tissue during the extraction procedure before elution through the calcium phosphate column. At the time of inoculation there was little idea as to the number of positive cases likely to arise from the passage of fractionated goat and sheep tissue in mice so that groups of large numbers of mice (30) were inoculated instead of attempting titration with smaller groups. The final eluates from the column were pooled in two batches comparable with the first sheep experiment.

Table 2. Incidence of scrapie in mice inoculated with calcium phosphate eluates of scrapie sheep (Suffolk) brain preparations at 12 months (370 days) post inoculation

\begin{tabular}{|c|c|c|}
\hline Expt. no. & Inoculum & $\begin{array}{c}\text { No. of } \\
\text { scrapie mice }\end{array}$ \\
\hline ME 43 & $S(10 \%)$ & $17 / 22$ \\
\hline ME 44 & $\mathrm{~S}_{1}$ & $17 / 24$ \\
\hline ME 45 & $0.05 \mathrm{M}$ & $19 / 27$ \\
\hline ME 46 & $\left.\begin{array}{l}0 \cdot 1 \mathrm{M} \\
0 \cdot 2 \mathrm{M} \\
0 \cdot 3 \mathrm{M}\end{array}\right\}$ & $0 / 17$ \\
\hline ME 47 & $\left.\begin{array}{l}0.4 \mathrm{M} \\
0.5 \mathrm{M}\end{array}\right\}$ & $0 / 25$ \\
\hline
\end{tabular}

Table 3. Incidence of scrapie in mice inoculated with calcium phosphate eluates of scrapie ('scratching') goat brain preparations

\begin{tabular}{|c|c|c|c|c|}
\hline Expt. no. & Inoculum & $\begin{array}{c}\text { No. of scrapie } \\
\text { mice } \\
\text { (321 days } p / i)\end{array}$ & $\begin{array}{c}\text { No. of scrapie } \\
\text { mice } \\
\text { (344 days } p / i)\end{array}$ & $\begin{array}{l}\text { Total no. of } \\
\text { scrapie mice }\end{array}$ \\
\hline ME 48 & $S(10 \%)$ & $4 / 5$ & $10 / 16$ & $14 / 21$ \\
\hline ME 49 & $S_{1}$ & $2 / 3$ & $18 / 22$ & $20 / 25$ \\
\hline ME 50 & $0.05 \mathrm{M}$ & $2 / 3$ & $0 / 18$ & $2 / 21$ \\
\hline ME 51 & $\left.\begin{array}{l}0 \cdot 1 \mathrm{M} \\
0 \cdot 2 \mathrm{M} \\
0 \cdot 3 \mathrm{M}\end{array}\right\}$ & $1 / 3$ & $1 / 21$ & $2 / 24$ \\
\hline ME 52 & $\left.\begin{array}{l}0 \cdot 4 \mathrm{M} \\
0.5 \mathrm{M}\end{array}\right\}$ & $1 / 3$ & $6 / 19$ & $1 / 22$ \\
\hline
\end{tabular}

Those groups of mice inoculated with sheep material (ME 43, 44, 45) developed general clinical symptoms of scrapie in mice at $11 \frac{1}{2}$ months after inoculation, and all the animals were killed at 12 months. Indications of scrapie in the mice inoculated with goat material were apparent at 10 months after inoculation. Histology confirmed scrapie activity in each group and all the animals were killed one month later. The incidence of scrapie is listed in Tables 2 and $\mathbf{3}$.

The histological appearance of the brains of infected mice from both sheep and goat material was identical, and the clinical symptoms were also relatively similar with goat material reacting about 1 month earlier. There was an $80 \%$ infectivity of sheep and goat tissue in 12 and 11 months, respectively. These results are not in 
precise quantitative agreement with other reported observations and illustrate that there is both a variation in the potency of source strain and probably also in the susceptibility of the mouse population used (see Zlotnik \& Rennie, 1963). The comparable level of activity in ME 43, 44 and ME 48,49 indicated that the activity was quite high in the pelleted material introduced to the column, but there was certainly no concentration effect as judged arbitrarily by the less marked clinical symptoms in these groups. With an assumption of complete recovery of scrapie agent, inoculum $S_{1}$ (ME 44) would have had 15 times the potency of inoculum $S$ (ME 43). Resuspension of this pellet, however, did give rise to a large amount of unsuspended sediment which could very well have carried a high proportion of activity. The sheep $0.05 \mathrm{M}$ eluate (ME 45) apparently had high activity which could indicate little adsorption of the active agent to the column. Repeat elution of the successive sheep fraction could eliminate any trailing or carry-over from weakly adsorbed material if this happened and would account for the absence of activity in the pooled fractions (ME 46, 47). The goat 0.05 M eluate (ME 50) had low activity, suggesting strong adsorption of the active agent to the column. The repeat elution of the goat fractions do show weak activity which, considering the possible losses throughout the procedure, is strong evidence for adsorption-desorption phenomena taking place.

\section{Inoculation of scrapie mouse brain (Chandler) fractions into mice}

The 10\% homogenate inoculum appeared to be normally active with $100 \%$ incidence over a period of $6 \frac{1}{2}-8 \frac{1}{2}$ months. The buffer-extracted preparation applied to the column was very inactive, with one mouse affected with scrapie. For concentration of activity this method of purification was therefore impracticable.

The mice receiving the $0.4 \mathrm{~m}$ eluate, where again one mouse was affected, were the only other group showing activity. Any trailing of the extremely low activity introduced to the column could be considered as negligible at this stage of the elution procedure. It appears possible to suggest that in relation to the low activity applied to the column the surprising appearance of scrapie in the $0.4 \mathrm{M}$ eluate was indicative of a concentration effect of adsorption-desorption phenomena in the column.

\section{Titration in mice of scrapie mouse brain (Suffolk) fractions after ether extraction}

An estimation of the distribution of the activity in the column eluates is given in Table 4. The LD 50, defined as that dilution of material which induced scrapie in half the animals inoculated, was calculated by the Reed \& Muench (1938) method. The standard error where possible was determined according to Thompson (1947). For a significant difference in LD 50 the values must differ by at least $0 \cdot 6$ (see Bachrach \& Schwerdt, 1952). The apparently low value of $10^{-4 \cdot 3}$ for the LD 50 of the original homogenate on comparison with other data available probably resulted from the sedimentation of activity by the comparatively high centrifugal force applied in this instance. Hunter \& Millson (1964), and Eklund, Hadlow \& Kennedy (1963) have both reported a decrease in LD 50, that can be estimated from their titration data as approximately $10^{-2}$, after ether extraction of an acetone powder extract 
and a Seitz-filtered preparation of scrapie mouse brain homogenate, respectively. The recovery here of activity in the suspension applied to the calcium phosphate column showed a comparable fall. The extraction procedure subsequent to ether treatment was, however, quite different. It is of interest that after resuspension of the solvent-extracted tissue a good recovery of the activity was found in the pellet after high-speed centrifugation of the supernatant fluid from a low-speed centrifugation that eliminated a considerable amount of tissue debris. Total recovery of activity from the column was probably in the range $40-90 \%$ as the inherent error in titration did not permit a more accurate estimation. The activity appeared

Table 4. Recovery and distribution of scrapie activity in calcium phosphate eluates of scrapie mouse (Suffolk) brain preparations

\begin{tabular}{|c|c|c|c|c|c|}
\hline Inoculum & $\begin{array}{l}\text { LD 50 } \\
-\log _{10}\end{array}$ & $\begin{array}{l}\text { s.e. of } \\
\text { LD50 }\end{array}$ & $\begin{array}{c}\text { Infectivity } \\
(\%)\end{array}$ & $\begin{array}{c}\text { Infectivity } \\
\text { in } \\
\text { column } \\
\text { eluate } \\
(\%)\end{array}$ & $\begin{array}{c}\text { Probable } \\
\text { spread } \\
\text { of eluate } \\
\text { infectivity } \\
(\%)\end{array}$ \\
\hline $10 \%$ hom. & $4 \cdot 3$ & $0 \cdot 33$ & 100 & - & - \\
\hline Ether prep. & $2 \cdot 6$ & $0 \cdot 14$ & $0 \cdot 6$ & 100 & - \\
\hline $0.05 \mathrm{M}$ & $\mathbf{2 \cdot 4}$ & $0 \cdot 14$ & - & 40 & 60-25 \\
\hline $0.1 \mathrm{M}$ & 2.0 & $0 \cdot 22$ & - & 16 & $36-6$ \\
\hline $0 \cdot 2 \mathrm{M}$ & $1 \cdot 4$ & - & - & 4 & $10-1.5$ \\
\hline $0 \cdot 3 \mathrm{M}$ & $1 \cdot 1$ & - & - & 2 & $5-1$ \\
\hline $0.4 \mathrm{M}$ & $<1$ & - & - & $(0 \cdot 4)$ & - \\
\hline $0.5 \mathrm{M}$ & $<1$ & - & - & $(0 \cdot 4)$ & - \\
\hline
\end{tabular}

Table 5. Distribution of scrapie activity in calcium phosphate eluates of scrapie mouse (Suffolk) brain preparations

\begin{tabular}{|c|c|c|c|c|}
\hline Inoculum & $\begin{array}{l}\text { LD 50 } \\
-\log _{10}\end{array}$ & $\begin{array}{c}\text { Protein } \\
\text { g./ml. } \\
\times 10^{-6}\end{array}$ & $\begin{array}{c}\text { Specific } \\
\text { LD 50 } \\
-\log _{10}\end{array}$ & $\begin{array}{l}\text { Relative } \\
\text { infectivity }\end{array}$ \\
\hline Ether prep. & $\mathbf{2 \cdot 6}$ & $77 \cdot 5$ & 5.01 & $1 \cdot 0$ \\
\hline $0.05 \mathrm{M}$ & $\mathbf{2 \cdot 4}$ & $5 \cdot 9$ & 5.93 & $8 \cdot 3$ \\
\hline $0 \cdot 1 \mathrm{M}$ & $2 \cdot 0$ & $2 \cdot 9$ & $5 \cdot 84$ & $6 \cdot 8$ \\
\hline $0.2 \mathrm{M}$ & $1 \cdot 4$ & $3 \cdot 0$ & $5 \cdot 22$ & $(1 \cdot 7)$ \\
\hline $\mathbf{0} \cdot \mathbf{3} M$ & $1 \cdot 1$ & $1 \cdot 8$ & $5 \cdot 15$ & $(1 \cdot 4)$ \\
\hline $0.4 \mathrm{M}$ & $<1.0$ & $(0 \cdot 6)$ & $(5 \cdot 0)$ & - \\
\hline $0.5 \mathrm{M}$ & $<1.0$ & $(0 \cdot 2)$ & $(5 \cdot 5)$ & - \\
\hline
\end{tabular}

to tail during progressive elution, falling broadly into three levels each reduced by a 10-fold dilution, viz. 0.05 and $0.1 \mathrm{M}(50 \%), 0.2$ and $0.3 \mathrm{M}(5 \%), 0.4$ and $0.5 \mathrm{~m}(0.5 \%)$. This fall appeared to follow the changes in the elution pattern as described in Fig. $1 a$. In order to estimate specific activity, the whole experimental procedure was repeated and protein- $\mathrm{N}$ determined on the final suspensions similar to those used for inoculation. The specific LD50 for each inoculum, defined as the concentration of protein in $\mathrm{g} . / \mathrm{ml}$. which induced scrapie in half the animals inoculated, are listed in Table 5. A significant improvement in relative activity is apparent in the 0.05 and $0 \cdot 1 \mathrm{~m}$ eluates. 


\section{DISCUSSION}

On the basis of the comparable ether extraction procedures applied to the mouse tissue titration experiment and the original sheep tissue experiment with testing of the eluates in sheep the tentative assumption could be made that the elution of scrapie activity might follow the same general pattern. If this were so then the pooling of the eluates in the sheep experiment would give effective dilutions of $10^{-1}, 10^{-1}, 10^{-2}$ and $10^{-3}$ in the column preparation $\left(S_{1}\right), 0.05 \mathrm{~m}$ eluate, $0.1 \mathrm{~m}$ pool and $0.4 \mathrm{M}$ pool, respectively. There is unlikely to be a significant variation in the response of groups of sheep within this range of dilution (Stamp et al. 1959) so that the incidence of scrapie ('Table 1) is in agreement with the assumption.

In the incidence of scrapie following inoculation of sheep and goat preparations into mice (Tables 2, 3), the numerical data indicate a contradictory adsorptiondesorption behaviour of the scrapie sources on calcium phosphate with a tendency towards specific adsorption of goat material. There is other evidence that the elution behaviour of the scrapie agent present in sheep, goat and mouse tissue may differ. A buffer extraction procedure, similar to that applied to the Chandler mouse brain, of scrapie sheep brain gave an inoculum of high potency when tested in sheep (Mould \& Smith, 1962a). The same extraction carried out with scrapie goat brain has been found to be apparently quite inactive in goats, while the mouse extract described here was only very weakly active. These findings are in agreement with the observed complete elution of activity from sheep material at $0.05 \mathrm{M}$-phosphate, poor elution of activity from goat material at $0.05 \mathrm{M}$-phosphate followed by elution of activity at higher concentrations and elution of activity from mouse material at 0.4 M-phosphate. After ether extraction of the tissue, however, both sheep and mouse eluates appear to behave somewhat similarly when biologically tested in the homologous animal, suggesting that ether treatment of the tissue can alter its elution behaviour.

The general conclusion is that elution of centrifuged preparations of scrapie brain tissue from sheep, goats and mice through calcium phosphate columns does not provide a method for concentration of the biologically active agent and purification of the agent is only marginal. The activity was always found in the pelleted sediment after high speed centrifugation of the eluates and the agent still appears to be closely associated with tissue fragments. There are likely to be species variations in the elution characteristics of the scrapie agent present in the brain tissue. More quantitative data are required on various aspects of the work. The adsorption-desorption behaviour of scrapie-active tissue fragments after further disruption by chemical and physical methods is at present under investigation.

We are indebted to Dr I. Zlotnik and Mr J. C. Rennie for the histological examination of mouse brain tissue. 


\section{REFERENCES}

Bachrach, H. L. \& Schwerdt, C. E. (1952). Purification studies on Lansing poliomyelitis virus: pH stability, CNS extraction and butanol purification experiments. J. Immunol. 69, 551 .

Butler, E. J. \& Smith, W. (1960). An attempt to separate the scrapie agent from brain tissue. Vet. Rec. $72,417$.

Chandler, R. L. (1961). Encephalopathy in mice produced by inoculation with scrapie brain material. Lancet, i, 1378.

Chandler, R. L. (1963). Experimental scrapie in the mouse. Res. vet. Sci. 4, 276.

Eklund, C. M., Hadlow, W. J. \& Kennedy, R. C. (1963). Some properties of the scrapie agent and its behaviour in mice. Proc. Soc. exp. Biol., N.Y. 112, 974.

Faulkner, P., Martin, E. M., Sved, S., Valentine, R. C. \& Work, T. S. (1961). Studies on protein and nucleic acid metabolism in virus-infected mammalian cells. Biochem. $J$. $80,597$.

Hunter, G. D. \& Millson, G. C. (1964). Further experiments on the comparative potency of tissue extracts from mice infected with scrapie. Res. Vet. Sci. 5, 149.

Hunter, G. D., Millson, G. C. \& Chandler, R. L. (1963). Observations on the comparative infectivity of cellular fractions derived from homogenates of mouse-scrapie brain. Res, vet. Sci. 4, 543.

Hunter, G. D., Mullson, G. C. \& Meek, G. (1964). The intracellular location of the agent of mouse scrapie. J. gen. Microbiol. 34, 319.

Logan, J. E., Manwell, W. A. \& Rossiter, R. J. (1952). Estimations of nucleic acid in tissue from the nervous system. Biochem. J. 51, 470 .

Lowry, O. H., Rosebrough, N. J., Farr, A. L. \& Randall, R. J. (1951). Protein measurement with the Folin phenol reagent. J. biol. Chem. 193, 265.

Mould, D. L., Dawson, A. McL. \& Smith, W. (1964). The infectivities of brain cell fractions from mice infected with Suffolk sheep scrapie agent. Biochem. J. 91, 13 P.

Mould, D. L. \& Smith, W. (1962a). The causal agent of scrapie. I. The extraction of the agent from infected sheep tissue. J. comp. Path. 72, 97.

Mould, D. L. \& Smith, W. $(1962 b)$. The causal agent of scrapie. II. Extraction of the agent from infected goat tissue. J. comp. Path. 72, 106.

Mould, D. L., Smith, W. \& Dawson, A. McL. (1963). The causal agent of scrapie disease of sheep. Biochem. J. 87, 24P.

Mould, D. L., Smrth, W. \& Dawson, A. McL. (1964). The elution of scrapie brain tissue through calcium phosphate columns. Biochem. J. 91, $13 \mathrm{P}$.

ReEd, L. J. \& MUENCH, H. (1938). A simple method of estimating fifty per cent end points. Am. J. Hyg. 27, 493.

Stamp, J. 'T., Brotherston, J. G., Zlotnik, I., Mackay, J. M. K. \& Smith, W. (1959). Further studies on scrapie. J. comp. Path. 69, 268.

Tiselius, A., Huerten, S. \& Levin, Ö. (1956). Protein chromatography on calcium phosphate columns. Archs. Biochem. Biophys. 65, 132.

Taverne, J., Marshall, J. H. \& Fulton, F. (1958). The purification and concentration of viruses and virus soluble antigens on calcium phosphate. J. gen. Microbiol. $19,451$.

Taverne, J. \& Wildy, P. (1959). Purification of herpes simplex virus by chromatography on calcium phosphate. Nature, Lond. 184, 1655.

Thompson, W. R. (1947). Use of moving averages and interpolation to estimate medianeffective dose. 1. Fundamental formulas, estimation of error, and relation to other methods. Bact. Rev. 11, 115.

Wildy, P., Stoker, M. G. P., Macpherson, I. A. \& Horne, R. W. (1960). The fine structure of polyoma virus. Virology, 11, 444.

Zlotnik, I. \& Rennie, J. C. (1962). The pathology of the brain of mice inoculated with tissues from scrapie sheep. J. comp. Path. 72, 360.

Zlotnik, I. \& Rennie, J. C. (1963). Further observations on the experimental transmission of scrapie from sheep and goats to laboratory mice. J. comp. Path. 73, 150. 